It is convenient to transform the logarithmic decrement into the half-period of decay. This gives the median absence :

Median absence $=\frac{0 \cdot 3010}{\log \text { decrement }}+3$ days.

The graphs show the method demonstrating a change in severity during the war years. Data are from one firm which has not changed its processes during this period, nor has there been any major change in the quality of labour employed. The disabling accident rate for 1938, 1939, 1940 is 86 per 100,000 man-shifts, and for 1941, 1942, 1943 it is 118 per 100,000 man-shifts. By themselves these figures suggest a large increase in risk during the later war years. Absence medians show a decrease in severity of reported accidents during the latter period (medians at $19 \cdot 96$ and $16 \cdot 27$ days for the two periods). Thus the increase in accident-rate can be attributed in part to increased willingness to report injury and to take immediate absence of short duration. The main social and economic changes likely to have caused this increased willingness to report and be absent are higher wages, more secure employment, revised compensation arrangements and regulations against absenteeism.

If we consider each year separately

$\begin{array}{ccc}\text { Year } & \begin{array}{c}\text { Kate per } 100,000 \\ \text { man-shifts }\end{array} & \begin{array}{c}\text { Median } \\ \text { absence }\end{array} \\ 1938 & 90 & 21 \cdot 9 \\ 1939 & 94 & 17 \cdot 7 \\ 1940 & 78 & 20 \cdot 5 \\ 1941 & 105 & 17 \cdot 7 \\ 1942 & 119 & 15 \cdot 4 \\ 143 & 131 & 16 \cdot 8\end{array}$

These show the general trend of increase in accidentrate and decrease in severity during the war years. The exception noted for 1940 is presumably to be explained by the overriding pressure of work in the summer and autumn of that year, when the workers realized the urgent need of supplies and considered personal injury of minor importance.

Similar treatment of data from other sources shows a difference in severity of accidents reported by fulltime workers and by part-time workers.

The conclusion is that reporting of sickness and injury in industry may be affected by factors unrelated to industrial risk. Comparative work must consider the severity of the reported cases. The median absence, obtained by the method described above, is recommended as a measure of severity.

J. W. WHITEIELD.

Medical Research Council

Unit of Applied Psychology,

Psychological Laboratory, Cambridge.

Oct. 14.

\section{Sampling of Cooked Cabbage in Nutrition Surveys}

IN the course of an investigation which we carried out at a local hospital during the winter, it became necessary to estimate the loss of ascorbic acid which occurred in cabbage in the interval between the completion of cooking and consumption in the wards and dining-rooms. This interval was usually between thirty minutes and one hour, during which time the cabbage was kept in water-jacketed boxes at $60-70^{\circ} \mathrm{C}$. We failed to obtain satisfactory duplicate analyses of samples taken in the hospital, and it was therefore

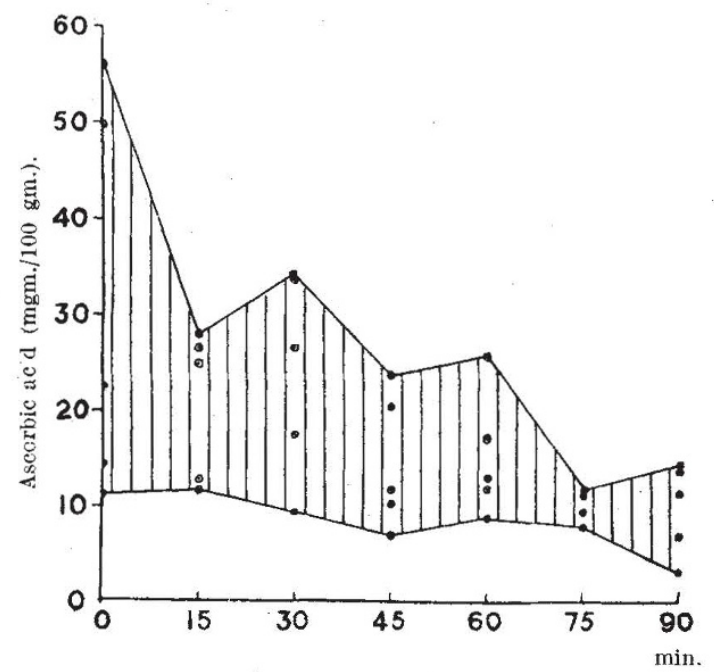

decided to carry out experiments under similar conditions in the laboratory.

Cabbage was cooked, strained and kept at $60-70^{\circ} \mathrm{C}$., samples being taken at intervals. The ascorbic acid content was estimated by titration with $2: 6$ dichlorophenol-indophenol, using a sulphuric acid/ metaphosphoric acid solution for stabilizing the vitamin between sampling and estimation. It was again not found possible to obtain agreement between either duplicate or triplicate samples. Reference to the literature in which satisfactory analyses are given $^{x}$ revealed the fact that the cabbage used was either minced or finely chopped. We can confirm that there is no difficulty in obtaining good agree. ment between replicate samples of cabbage under these conditions. But a difficulty arises when it is not possible to use methods for homogenizing the cabbage, as in field work, where samples taken for analysis are usually those actually put out on to plates during the service of the meal. The results given in the papers referred to above apply only to ideal conditions which are rarely encountered in work of this sort.

An example of our results is given in the accompanying graph, which shows an attempt to construct a curve recording the loss of ascorbic acid on keeping cabbage hot. Five samples were taken at each time interval. An even wider variation in values was obtained when ten samples were taken ; for example, 32-75 mgm.; 25-78 mgm. and 11-56 mgm. per $100 \mathrm{gm}$. cabbage. Some of these values are as much as \pm 70 per cent from the mean. Care was taken that the samples analysed did not consist almost entirely of stalk or of leaf.

The experiments suggest that in field work, where an attempt is made to assess the ascorbic acid content of food actually consumed, it is not possible to obtain trustworthy results unless the food is normally mashed or minced before serving.

$$
\text { H. G. Bray. }
$$

W. V. Thorpe.

Department of Physiology, Medical School, Hospitals Centre, Birmingham, 15.

1 MeHenry and Graham, Biochem. J., 29, 2013 (1935). Olliver, J. Soc. Chem. Ind., 55, 153T (1936). Gould, Tressler and King, Food Res., 1, 427 (1936). Stone, Biochem. J., 31, 508 (1937). Olliver, Chem. and Ind., 587 (1941), Lampitt, Baker and Parkinson, J. Soc. Chem. Ind., 62, 61 (1943). 